\title{
An Analysis of The Treatment and Pushing Hands from the Perspective of Intercultural Communication
}

\author{
Jianjun Wang \\ Foreign Languages College, Inner Mongolia University, Hohhot, 010021, China \\ Chunyan Sun \\ Foreign Language Teaching Department, Inner Mongolia University for the Nationalities, Tongliao, 028000, China
}

\begin{abstract}
This paper which is on the basis of two movies, The Treatment and Pushing Hands, mainly demonstrates cultural differences and conflicts between China and the west, and analyzes them in some aspects as well as the causes of it. And finally it also probes the ways to settle the cultural conflicts on the basis of the analysis.
\end{abstract}

Index Terms-The Treatment, Pushing Hands, cultural differences and conflicts, China and the west, intercultural communication

\section{INTRODUCTION}

During the process of intercultural communication between China and the west, Chinese have always been advocates and practitioners. The Silk Road, Zheng He's Voyage to the west, as well as the Westernization Movement are all the best telling witnesses. Four great inventions of China spread to Europe through the communication of Chinese and western cultures, which played an important part in driving the development of Europe and even the whole world (Li Xinliu 2005, p.99). With the development of globalization, the economic and social connections of cross-nations, cross-languages and cross-cultures are increasing, which result in the appearance of cultural conflicts. Nowadays, a large number of literary works and movies turn to the conflicts of multi-cultures and meanwhile Chinese directors attempt to show the whole world the traditional culture of Chinese nation. There is no doubt that the movie plays an important role in knowing about western cultures, with the popularization of internet in China. A classical movie is often a brief summary and conclusion of the realistic society. By watching classical movies, we can experience the charm and essence of western cultures to make up ours, and learn about the differences or conflicts between Chinese and western cultures so that we could communicate with each other better.

The founder of intercultural communication, Mr. Hall ever expressed: Culture exists in two levels, public culture and hidden culture. The former is visible and easy to be described, but the latter is invisible - even the specially trained observer can't find it. It is because of the existence of the hidden culture that makes cultural conflicts become a kind of objective existence. The Treatment which was made by the director Zheng Xiaolong in 2000 and Pushing Hands which was made by the director Li' an in 1992 are two typical movies showing us the cultural conflicts between China and the west in aspects of outlooks on life, values, moral ethics, family humanities, friend relationship, national tradition and thinking patterns. Some of the cultural conflicts will be discussed as follows.

\section{The Main Cultural Conflicts in The TREatment and Pushing Hands}

First of all, let's have a discussion about the conflicts of family values between Chinese and western cultures. Since ancient times, China was a country connected with blood ties and clan relations. Traditional family ethics stem from the social and political structures connected with blood ties and clan relations, self-sufficient economy, and group-oriented values. The traditional family ethics above has its own characteristics, indicating family-centered, father-son relationship-valued, and piety-oriented. (Li Guimei 2002, p.1) Traditionally, Chinese people prefer extended families, especially three generations or even four generations at one roof which represents happiness. In Pushing Hands, Xiaosheng, a Chinese striving in America has adjusted to the American culture. But influenced by traditional Chinese culture, Xiaosheng had a strong sense of extended family value, the filial piety to the elders, and also took it for granted to support and take care of their parents. On account of it, he brought his father to America to enjoy the company of their families. However, this kind of extended-family pattern is quite different from the western one.

There is no very traditional culture in America. And more importantly, America is a huge country of immigrants. The deficiency of traditional civilization, the effect of immigration and western culture make American people full of self-awareness, that is to say, they emphasize individual-oriented culture, pay great attention to private rights and privacy, and require their own space and independence. In the west, children who are at or over the age of 18 will 
choose to leave home to make their own living whether they are married or not. It is quite unbelievable for them to live with their parents. However, children's independence does not mean they give up their parents. They will visit their parents on weekends or holidays. American parents value their children's spirit of independence and their own independent life when they are getting old. Therefore, the elder in America are reluctant to live with their adult children even though they have fantastic economic conditions. In western cultures, people praise the spirit of the independence, unwilling to count on their relatives. The value orientation in western cultures gets more individualistic. (Zhu Xiying, Xu Shuxia, 2005, p.224) Similarly, when discussing the issue of caring for the elder, most of the elder take it for granted that it is themselves rather than others that they should rely on even though they are over 80 years old, and their adult children are no exception, or if necessary they would go to the nursing home. This type of family pattern and family ties are quite unacceptable to Chinese. In China, if the young generation sent the elder to the nursing home, people around them would believe the elder are unfortunate and their children are not filial to the elder.

Therefore, the core of traditional Chinese family ethics is harmonious, while independence is emphasized by the westerner. That is Chinese group orientation and western individualism orientation. For example, in Pushing Hands, at the beginning, it was very difficult for Xiaosheng's American wife to understand the reason why they had to live with her father-in-law, who entered her personal space. She was a writer with enthusiasm which meant she stayed at home very often, while her father-in-law made her distracted when she focused on her writing. According to American family value, they prefer the nuclear family which just includes parents and their underage children, and do not include grandparents. So she argued that her father-in-law should not live with them and persuaded her husband to send the old man to the nursing home which was completely in line with American family values. Xiaosheng was in a dilemma and not sure what was the best way to deal with the conflicts between his Chinese father and American wife. After the old man moved out, she concentrated on her writing and her book was highly accepted, all of which seemed to suggest that the parents should not live with their children.

As we know, respecting the elder is a good social atmosphere in China, which doesn't influence the westerners' mind. In Pushing Hands, Martha, as a daughter-in-law, never treated her father-in-law with full respect in a Chinese way. In contrast, she often interrupted while he was talking. That is to say, she destroyed a Chinese father's authority in the family. Actually, for a long time, Xiaosheng's father had been treating himself and the relationship between him and his son's family as a Chinese way. He treated his son's home as his own; he did whatever he wanted in the house, such as watching TV, singing Peking Opera, exercising, etc., regardless of Martha's feelings. After a series of conflicts with Martha, he finally realized that American family values were quite different from that of Chinese and his son's home was no longer his own, so he had to adjust to American culture.

Second, let's compare Chinese emotions and western sensibility. In China, friend relationship ranks only second or equals the relationship among family members. Honesty and trust are very important in friendship. Friends can help you out no matter when you are in trouble. But if you betray your friends and do something to harm the interests of your friends, you will be condemned by your friends and even the whole society.

In the Treatment, when Datong's family was involved in the lawsuit, he asked his best friend Boss Quinlan for help. Although his boss dealt mostly in the cases of intellectual property right, Datong still trusted him because he treated his boss as a real friend. Datong thought his boss would try to defend him, no matter what happened. However, Quinlan was convinced by the picture that the child was under child abuse for quite a long time and refused to defend Datong out there. Because westerners are rational rather than emotional. On the processing of business, they still obey the law even though it had something to do with their relatives or friends. Not only that, influenced by the honest education from Christianity, Quinlan stood on a witness stand. Honesty is the best policy. However, it was unacceptable for Datong, because he thought that his friend betrayed him according to Chinese Morality and Ethics. Although his boss explained to him over and over later and asked for his forgiveness, Datong still refused to talk to him. Datong, as a Chinese, thought that it was the right thing to break up with his boss.

In this movie, Chinese emotions and westerner's sensibility conflicted violently. Later, Quinlan figured out the truth by experiencing "the treatment" personally in China. He then told the lawyer and judge what he had been through and eventually helped Datong's family out. They became friends again which also shows the common characters between Chinese friendship and western friendship, namely, friends should help each other, and never give up on each other.

Third, the misunderstanding of the essence of traditional Chinese culture must be mentioned. In the film The Treatment, the focus of the conflicts between Chinese and western culture is whether "the treatment" is legal or not. "The Treatment", the essence of traditional Chinese medical treatment, which is legal, has been popular for its excellent efficiency for thousands of years in China. However, it was thought as child abuse by American people. The traditional Chinese treatment, which could not be proved its rationality, was not recognized in America, because American people knew little about traditional Chinese medicine. Xu Datong tried his best to explain what is "the Treatment" in English and sometimes in Chinese (such as Dantian - lower abdomen, seven jing and eight mai) in court, which was difficult for American people to understand, for there were no corresponding words in American culture. As the attorney for Datong said, there was nothing about "the Treatment" in any American medical textbook, so it was unscientific and nobody would testify its legality. Maybe Datong's father and most of Chinese audience would take it for granted that it was American people's fault, because they were not familiar with "the Treatment", a common traditional Chinese medical treatment. Actually, we should not impose our culture to another culture in cross-cultural communication. 
Martial arts, the other essence of traditional Chinese culture, is the gem of Chinese traditional culture. With the increase of international communication, more and more foreigners are crazy about Chinese martial arts, which are becoming one of the world cultures. The birth and development of Chinese martial arts are dependent on the intelligence of Chinese ancestors. Chinese martial arts aim to keep fit and be against violence. However, many people in western countries still misunderstand Chinese martial arts as violence. For example, in the movie Pushing Hands, when Xiaosheng's father complained that Xiaosheng and Martha indulged his child in the cartoons with violence, Martha dismissively refuted: "He's complaining? He (Martha's father-in-law) is a martial arts expert himself. Isn't it violent enough?" Obviously, she misinterpreted the essence of Chinese martial arts.

What's more, let's discuss the issue of face concern. Family members will adopt different methods of face concern, because of different ideas of family values between China and the west. On the basis of hierarchy in the family and traditional Chinese filial piety culture, Chinese parents and their children live in a system of hierarchy and courtesy while American family members live in a system of respect and courtesy, on the basis of the concept of individualism orientation, freedom, democracy and equality. As one of the complete equal family members, the parents or their children are independent, and respect each other's space and willingness. (Gong Xiaoping 2007, p.108-109)

In the Treatment, Datong's son Dennis fought with Quinlan's son, and Dennis was not willing to apologize as his father' order, so he was slapped by his father in front of Quinlan couple. As we know, Datong just wanted to show his respect for his boss and friend, Quinlan, by punishing his son according to Chinese way of education. Obviously, it is traditional Chinese view of face concern, which is understood by anyone who lives in China or who ever lived in China. However, it was so difficult for Quinlan to understand Datong's conduct, which is unseemly in American people's eyes.

The Chinese and the westerner interpret face concern differently. China is a country of face-saving. In traditional Chinese concept, you can lose anything except losing face. In most cases, the Chinese tend to show respect as well as save each other's face by belittling themselves, as explains why Datong beat and scolded his beloved son to save Quinlan's face. This was deemed as stupid by Americans whose core of cultural values is individualism, not to mention respecting others. In any case, the American cannot understand the concept of face-saving. The westerners have their own idea of face concern, which is an image that every individual tries his best to earn in the public. Chinese idea of face-saving is one form of collectivism, that is to say, the Chinese hope to be recognized by others in the specific collective. Whereas, the westerners are in seek of independent characters, just caring about his own success and satisfaction and never minding other people's comments on what he said and did. In short, the idea of face concern between China and the west is quite different.

In addition, let's turn to different educational methods in different cultures. Generally children in the west accept liberal education from an early age. They have to know making choices by themselves will make up a powerful force, which enables them to be creative and maintain good relationships with others. Because of love, parents must guide their children not to lag behind in the competition and encourage them to learn to do things themselves. (Xiao Qunzhong 2001, p.420) For example, in Pushing Hands, Jimmy interpreted his own edited book for Martha. There was a turtle, a fish, a mouse and a pool of liquid medicine. And finally all of these went to hell. It seemed that Martha did not know the relationship among them, but she still praised Jimmy: "Jimmy is so creative!" Maybe Chinese parents will comment on the book: "it is so bad, I cannot understand!" we can see that American parents tend to respect their children's opinions and encourage them. In their eyes, it is impossible for anyone to limit the development of children, not to mention imposing their own values on their children.

On the contrary, Chinese would prefer to pass on wisdom and experiences to the young generation. For example, in Pushing Hands, the grandpa hopes to pass more Chinese cultures to Jimmy, such as learning to write Chinese characters, learning calligraphy and so on. On the other hand, generally speaking, Chinese parents always ask their children to do as what they said. And the parents especially the grandparents are keen in doing everything for children, such as doing some washing for them which actually deprives children's rights of living independently.

Last but not least, China is a society of human relationship and sometimes emotions will be superior to the law while western countries are legal societies in which the law is sacrosanct. In America, if you lied in the court, it was possible for you to be charged with perjury and be put into the prison. Datong had been in America for more than ten years, so he knew clearly the consequence of his lying. However, in order to protect his father, his personal emotions prevailed over his sensibility in the risk of breaking the law, and Chinese called it filial piety. Obviously, sometimes in China, emotions will be above the law. While for American people, what Datong did was impenetrable. There appeared a conflict between Chinese emotions and American value of respecting the law. In The Treatment, Datong lied to the judges that he took the treatment rather than his father. Also in order to be reunited with his family on Christmas Eve, Datong dressed as Father Christmas climbed up the ninth floor risking his life. The above mentioned, which cannot be allowed in accordance with American law, showed us a Chinese-style deep sense of kinship. As for Datong, it was ridiculous to provide the judges with the evidence that he loved his own son. What's more, the judges needed the evidence to prove "the Treatment" was legal in America, but it was so hard for Datong to get any material about it. So "the Treatment", a legal traditional Chinese medical treatment, which has been famous for its excellent efficiency for thousands of years in China, was thought as child abuse by American people. All of these reflect the opposition between Chinese-style emotions and the law of America. 


\section{The Causes of Cultural Conflicts}

The differences between modes of thinking, national customs, mentalities and attitudes towards nature lead to the cultural conflicts between China and the west, therefore, it is necessary for us to probe the root of the cultural conflicts between China and the west. The details will be discussed as follows:

One of the causes is different modes of thinking. Oneness between heaven and man paying attention to intuitive integrity and having the characteristics of image thinking and imagery thinking constitutes a mode of thought in Chinese philosophy. From the image "crow feedback", the Chinese will think of how to reward their parents, which is dependent on the association and imagination. Whereas, the westerners divide the world in half, which is substance and spirit, subjectiveness and objectiveness. People would like to analyze what they feel with rational principle putting aside emotional elements. (Hao Lili, Yang Xiaofeng 2007, p.1-10)

The differences between the modes of thinking have been reflected in the film The Treatment. For example, in court, the prosecution attorney inferred that Datong had a tendency of violence, just because Datong ever told his son the story about Sun Wukong (孙悟空) eating the peach slinky and making havoc in heaven in Journey to the West. Apparently by means of logical thinking, the prosecution attorney reasoned, judged and then drew a conclusion. In Chinese opinion, what the attorney did was ridiculous. However, it was recognized by the judges, for they had the same cultural background. The prosecution attorney and the judges could not understand the underlying culture in the Journey to the West, and it was impossible for them to associate, imagine and even enjoy the underlying culture just as Xu Datong.

And the second cause is the different national customs. Here we have to mention the plot again in the movie that Datong slapped his son to show his respect for his boss Quinlan, however, Quinlan could not understand. Actually, what Datong did was typical of Chinese-style educational method and attitude. For Datong and his father, they both agreed that it was right to beat children as an educational method. It seemed that this kind of authoritative education, feudal management and strict discipline of Confucian ethics had become traditional customs in China. By contrast, the westerners emphasized human right, advocated individual character, and claimed people-oriented deed. Everyone is equal whether you are a father-son relationship or a husband-wife relationship. They believe that children and their parents enjoy equal rights, so the parents cannot beat their children and cannot leave them alone at home in accordance with American law. In fact, Americans inspire and guide children in the education without violence. So now we can understand why Quinlan could not understand what Datong did, and why the parents leaving the child alone at home violated the American law.

The difference between mentalities and attitudes is another cause of cultural conflicts. In China, out of courtesy, people would like to say what you like, no matter which is true or not. While for American people, it is dishonest to say hypocritical words, and what matters most is sincerity and trust. For example, in America, if you say a bad thing about a person, the most offensive remark is: "You can not trust him". In the movie The Treatment, Quinlan said the truth that he thought, which deeply hurt the feelings of Datong. Datong thought Quinlan betrayed him. Whereas, Quinlan thought himself right, what he did was nothing with the friendship between them.

Last, let's discuss different attitudes towards nature. The Chinese attach importance to the harmony between human beings and nature. China is a time-honored agricultural country, so farmers in China have the customs to worship the heaven and the earth to pray for good weather, and bumper grain harvest in the coming year. During natural disaster farmers will worship the heaven to bless them while during good harvest they will express their thanks. Therefore, human beings are closely related to nature. However, people in the west pay much more attention to the conquest and reformation of nature for the survival and development of human beings. For example, Newton put forward the theory of universal gravitation and optical theory; Watt invented the first steam locomotive; the famous American writer Ernest Hemingway created the novel The Old Man and the Sea.

Above all, cultural differences in different countries won't necessarily happen, they are the consequences of comprehensive functioning of various factors in the long history of thousands of years, rather than being influenced by merely a certain factor.

\section{The Suggestions for Settling Cultural Conflicts}

In western culture, individualism protrudes social problems, while in Chinese culture, the idea of inaction set China back decades or even hundreds of years compared to western developed countries. Therefore, by learning from each other, eastern and western cultures will regain vitality and new life.

To tell the truth, we must criticize the ideology of two extremes: completely rejecting western culture and overall westernization. Chinese scholars have made great efforts in finding out the solutions to the conflicts between eastern and western cultures. Both totally repudiating western culture and total westernization should be given up. Chinese culture fully demonstrates its charm in a time of extreme individualism and belief crisis. If Chinese are totally westernized and abandon traditional Chinese culture, traditional Chinese social structure will be damaged, and social politics, economy and culture will be in imbalance. In the process of reform and opening up in China, the values of collectivism fully arouse the enthusiasm of people from all walks of life, enhance the cohesion of Chinese people of all ethnic groups and promote the development of reform and opening up. The achievements of China's reform and opening up prove that western culture is not the sole reference to modern culture and global cultural system; "western 
center theory" can't hold water. (Jin Yuanpu, Tan Haozhe, Lu Xueming 1999, p.707)

On the other hand, harmonious and different value concept has positive significance to cultural integration, which has been identified by many scholars. Habermas, a German sociologist is one of them. He thought justice and solidarity are two important principles which must be followed when different cultures are seeking dialogues. The former must guarantee each nation's cultural independence, because it owns the rights of developing itself; the latter refers to the culture whose duty is to sympathize with, understand and respect other cultures. (Lin Surong 2011, p.47) The culture will either continue to exist or it will decline among the conflicts of heterogeneous cultures. (Jiang Ningkang 2005, p.31-32) First, a kind of culture needs its special basis, and then moves with times and absorbs positive factors, which will make itself much wider, more fulfilling and more vigorous. (Xie Shaobo, Wang Fengzhen 2003, p.4) The development of Chinese culture and world civilization shows that harmonious and different value concept will be in the leading position of cultural development and social progress. Only by strengthening intercultural communication and mutual integration can all kinds of cultures achieve common development.

At the end of the movie The Treatment, we can also find cultural integration in it. Quinlan who was touched by what Datong did, dropped his prejudice and experienced Chinese culture. He experienced "the Treatment" himself and felt amazed at its wonderful treatment. Eventually, the gap between him and Datong was eliminated as well as the gap between Chinese culture and American culture, and the two cultures started to integrate.

\section{CONCLUSion}

Cross-cultural communication among different countries is the only way to keep cultures dynamic. The communication between different cultures has been repeatedly proved a kind of milestone in the development of human civilization. When we compare two cultures, donot determine the relative merits of Chinese and western cultures, but indicate the mainstream of two cultures. It will be easy for people from different cultural backgrounds to understand, communicate with and learn from each other and build an ideal human civilization. As a result of the limitation of various factors, most of us cannot experience cultural differences abroad. The only way for us to know western cultures is to get access to books and movies. By introducing two well-known movies and analyzing cultural conflicts in them, the paper explores the causes of cultural differences and conflicts and presents suggestions for settling them.

\section{REFERENCES}

[1] Gong Xiaoping. (2007). Comparison and Scrutiny of China and US family culture. Movie Review, 20, 108-109.

[2] Hao Lili, Yang Xiaofeng. (2007). A Tentative Analysis of Differences and their Language Effect Between Chinese and Western Thinking Mode. Journal of Shenyang Architectural University (social science edition), 9, 1-10.

[3] Jiang Ningkang. (2005). American Culture Interpretation. Shenyang: Liaoning Education Press.

[4] Jin Yuanpu, Tan Haozhe, Lu Xueming. (1999). Overview of Chinese Culture. Beijing: Capital Normal University Press.

[5] Li Guimei. (2002). Conflicts and Integration - Modern Turning and Values of Traditional Family Ethics in China. Changsha: Central South University Press.

[6] Li Xinliu. (2005). Introduction to Comparing Eastern and Western Culture. Beijing: Higher Education Press.

[7] Lin Su-rong. (2011).Conflicts and Integration Between Chinese Culture and "the Other" Culture in the Film of Gua Sha (Treatment). Journal of Putian University, 4, 44-48.

[8] Xiao Qunzhong. (2001). Filial Piety and Chinese Culture. Beijing: the People's Publishing House.

[9] Xie Shaobo, Wang Fengzhen. (2003). Interviews of Cultural Research. Beijing: China Social Science Press.

[10] Zhu Xiying, Xu Shuxia. (2005). Overview of Chinese and Western Culture. Beijing: China Light Industry Press.

Jianjun Wang was born in Inner Mongolia, China. He is currently an associate professor in Foreign Languages College, Inner Mongolia University, China. His research interests include intercultural communication and translation.

Chunyan Sun was born in Inner Mongolia, China. She is currently a lecturer in Foreign Language Teaching Department, Inner Mongolia University for the Nationalities, China. Her research interests include intercultural communication and translation. 